in vivo $35: 681-691(2021)$

doi:10.21873/invivo. 12308

Review

\title{
Osteochondromas: An Updated Review of Epidemiology, Pathogenesis, Clinical Presentation, Radiological Features and Treatment Options
}

\author{
KOSTAS TEPELENIS $^{1}$, GEORGIOS PAPATHANAKOS ${ }^{2}$, AIKATERINI KITSOULI ${ }^{3}$, \\ THEODOROS TROUPIS ${ }^{4}$, ALEXANDRA BARBOUTI ${ }^{3}$, KONSTANTINOS VLACHOS $^{1}$, \\ PANAGIOTIS KANAVAROS ${ }^{3}$ and PANAGIOTIS KITSOULIS ${ }^{3,5}$ \\ ${ }^{1}$ Department of Surgery, University Hospital of Ioannina, Ioannina, Greece; \\ ${ }^{2}$ Intensive Care Unit, University Hospital of Ioannina, Ioannina, Greece; \\ ${ }^{3}$ Anatomy - Histology - Embryology, University of Ioannina, Ioannina, Greece; \\ ${ }^{4}$ Department of Anatomy, Medical School, National and Kapodistrian University of Athens, Athens, Greece; \\ ${ }^{5}$ Orthopaedics, University of Ioannina, Ioannina, Greece
}

\begin{abstract}
Osteochondroma, the most common benign bone tumor, is a projection on the external surface of the bone, which can be sessile or pedunculated. $85 \%$ of osteochondromas present as solitary lesions, while $15 \%$ occur in the context of hereditary multiple exostoses (HME), a genetic disorder that is inherited in an autosomal dominant manner. Although often asymptomatic, symptoms may eventuate from compression of adjacent vessels or nerves, fractures, osseous deformities, bursa formation, or malignant transformation. Cartilage cap thickness $>2 \mathrm{~cm}$ in adults or $>3$ $\mathrm{cm}$ in children as well as new onset of pain or growth, or rapid growth of the lesion, especially after the closure of the growth plate, might reflect cancerous transformation. Surgical resection is indicated for symptomatic lesions, complications, cosmetic reasons or malignant transformation. Excision of the tumor with free margin is the treatment of choice. Local recurrence is less than $2 \%$ if complete resection is achieved.
\end{abstract}

Osteochondroma is the most common benign bone tumor accounting for $20-50 \%$ of benign bone tumors and $9 \%$ of all bone tumors (1-3). It is defined as a cartilage-capped bony

This article is freely accessible online.

Correspondence to: Kostas Tepelenis, MD, MSc, Vellas 30, Kardamitsia, Ioannina, Greece. Tel: +30 2651038047, Fax: +302651077630, e-mail: kostastepelenis@gmail.com

Key Words: Osteochondroma, exostosis, HME, imaging, chondrosarcoma, review. projection on the external surface of a bone $(2,4)$. The lesion may grow during childhood, but no osteochondroma develops or enlarges after puberty $(5,6)$. Two pathognomonic features that ascertain the diagnosis are the presence of cortical and medullary continuity with the parent bone and a cartilage cap $(7,8)$. Most lesions are solitary, but approximately $15 \%$ of the patients have multiple tumors (6).

Multiple osteochondromas are developed in the context of multiple hereditary exostoses (HME), a rare genetic disorder that is inherited in an autosomal dominant manner $(2,9)$. In the literature, HME has also been referred to as multiple hereditary osteochondromas, hereditary deforming dyschondroplasia, diaphyseal aclasis, and multiple cartilaginous exostoses (10). The majority of patients have a positive family history, while mutations in one of the EXT genes can be detected in about $90 \%$ of the HME cases $(11,12)$.

Traditionally, most osteochondromas are incidentally diagnosed as they are symptomless $(2,4)$. Complications associated with osteochondromas are common and encompass compression of adjacent structures, fractures, osseous deformities, bursa formation with or without bursitis, and malignant transformation $(2,7,13)$. Malignant transformation is more frequent in HME than solitary osteochondromas (6, 14). Plain radiographs are usually sufficient to diagnose osteochondromas, whereas cross-sectional imaging such as multidetector computed tomography (MDCT) and magnetic resonance imaging (MRI) are used to evaluate the cartilage cap, marrow continuity with the parent bone in complex areas, and complications $(3,4,15)$. Asymptomatic lesions are treated solely with observation, while symptomatic lesions or lesions with suspicious imaging findings require surgical resection. 
Surgical treatment is more common in HME than solitary lesions because of the increased risk for cancerous degeneration and osseous deformation $(1,16)$.

In a previous article we have summarized the clinical, radiological and pathological features of osteochondromas (4). The purpose of the present article is to review the updated findings regarding epidemiology, pathogenesis, clinical presentation, malignant transformation, imaging findings, treatment options and prognosis of osteochondromas.

\section{Epidemiology}

The exact incidence of osteochondromas is unknown since many of these tumors are asymptomatic and therefore remain undiagnosed. Besides, the incidence varies depending on the type. Solitary osteochondroma is approximately six times more frequent than HME (6). It is generally found within the first four decades, with $75 \%$ of such lesions arising before the age of 20 years $(4,17,18)$ showing a male predominance $(5$, $7,19,20)$. The estimated frequency of HME in the Western population is $1.5 \%$ per year (19) and its incidence is 1:50,000 persons $(21,22)$. It is encountered during the first decade of life in more than $80 \%$ of patients $(23,24)$ and has a predilection for males (male to female ration 3:1) $(19,20)$ and Caucasian (4). Patients with HME have a positive family history in about $65 \%$ of the cases (25-27). According to a relatively recent epidemiological study in South China, osteochondromas are frequently found during the first two decades of life and show a male predominance. However, only $14.7 \%$ of patients with HME have a positive family history, which is much lower than the reported rate in Western countries (28).

Almost half of them are located around the knee (29). Long bones are the preferred site, particularly distal femur $30 \%$, proximal tibia $15-20 \%$, and humerus $10-20 \%$, followed by feet and hands $10 \%$. In these bones, osteochondromas are situated at the metaphysis and grow away from the joint (30). In China, osteochondromas are situated around the knee in about $50 \%$ of the cases. Long bones of the lower extremities are at higher risk for the development of these tumors. Even though the two top locations are the same (distal femur and proximal tibia), proximal fibula ranks third place for osteochondromas instead of the humerus (28).

Flat bones such as sternum, scapula, ribs, and hips are involved in less of $5 \%$ of cases (1). Solitary osteochondromas are rarely located at the spine (4), whereas $68 \%$ of patients with HME have spinal osteochondromas (31). Although any part of the vertebral column can be affected, the cervical spine is involved in $50 \%$ of the cases (1), especially $\mathrm{C} 2$ vertebra followed by C3 and C6 $(32,33)$. The second most frequent location is the thoracic spine, particularly $\mathrm{T} 8$ vertebra followed by T4, whereas the lumbar spine is the least common site $(1,31,34)$.
The natural history of osteochondromas in children and adolescents was enlightened by a large Italian cohort study, which included 158 children with multiple osteochondromas. Overall, $80.4 \%$ of patients developed new osteochondromas, $57.6 \%$ developed new deformities, and $23.4 \%$ developed further functional limitations. The mean incidence rate of new osteochondromas, deformities and functional limitations increased with time. The annual rate, as well as the proportion of patients with new osteochondromas and deformities, was higher in the two younger age groups (0-6 years age group and 7-12 years age group) compared with the oldest age group (13-18 years age group) at all follow-up times (12, 24, and 36 months). When it comes to functional limitations, the 0-6 years age group showed a higher proportion of such limitations compared to two other age groups. As for the height, it seemed that 13 years was a cut off age for the slow growth of the stature (35).

\section{Pathogenesis}

HME is associated with heterozygous loss-of-function mutations in the EXT-1 and EXT-2 genes (12). EXT-1 is located on chromosome 8q24.11-q24.13 and EXT-2 on chromosome 11p11-12 (4). A variety of mutations in these genes in HME patients is present, including nonsense mutations, missense mutations, frameshift mutations, and splice-site mutations (36). In European patients with HME, mutations in the EXT-1 and EXT-2 genes are found in more than $90 \%$ of the cases, particularly $65 \%$ in the EXT- 1 gene and $21 \%$ in the EXT-2 gene (37). In contrast, Chinese patients have a higher rate of EXT-2 mutations than EXT-1, suggesting that EXT mutations depend on the ethnicity and different types of mutations contribute to the pathogenesis of HME differently (38). Francannet et al. discovered that patients with EXT-1 mutations are more severely affected as they develop more osteochondromas, suffer more severe symptoms, and are more likely to develop cancerous degeneration (37).

The EXT family encodes glycosyltransferases, which are vital for the synthesis of heparin sulfate (HS), a polysaccharide material that binds to core proteins to produce heparin sulfate proteoglycans (HSPGs) $(39,40)$. HSPGs are present to a large extent in the cell membrane and extracellular matrix and interact with bone morphogenetic proteins participating in the regulation of bone and cartilage formation (12).

Heterozygous mutations of the EXT-1 or EXT-2 gene lead to an HS deficiency of about $50 \%$; this is inadequate for giving rise to osteochondroma formation. But a second genetic hit such as a loss-of-heterozygosity or aneuploidy lowers further the HS levels, resulting in local cells losing their normal phenotype and turning into tumorigenic cells $(41,42)$. Though EXT-3 gene plays a vital role in the synthesis of HS, no such mutations have been detected in HME patients (11). 
An original nonsense mutation in the EXT2 gene (9c.526C>T; p.Gln176*) was identified in a Chinese family with HME from Hangzhou. The family consisted of 12 members belonging to three generations, four of whom had HME. The mutation was detected in all four patients, but not in their healthy relatives. The substitution of cytosine by thymine led to the appearance of a stop codon where previously there was a codon specifying glutamine. The presence of this premature stop codon resulted in the production of a shortened protein that lacked the last 552 amino acids at its C-terminal. As a result, the glycosyltransferase domain was missing as it is located at this terminal. Therefore, the HS production was affected because the glycosyltransferase domain plays a vital role in HS biosynthesis (43).

In addition, the first case of gene fusion as a mechanism of EXT1 loss of function in HME was recently reported by Oliver et al. The authors described the case of a 9-year-old male with multiple abnormalities, including HME. Whole transcriptome sequencing revealed the fusion of the 3boundary of SAMD12 exon 2 to the 5-boundary of EXT1 exon 2. Chromosomal deletion of the genomic region between SAMD12 exon 2 and EXT1 exon 2 was responsible for this event. The fusion brought about an interruption of the reading frame, which was equivalent to a loss of function of both genes (44).

Solitary osteochondromas were initially considered to be a developmental abnormality, in which a fragment of the growth plate herniates through the periosteum and, continuing growing, forms eventually a solitary osteochondroma $(1,2)$. Somatic mutations in the EXT genes are sporadic in solitary osteochondromas (4). However, recent studies demonstrated that heterozygous mutations in the EXT-1 gene are detected equally in solitary osteochondromas and HME, while mutations in the EXT-2 gene are infrequent in solitary osteochondromas. These findings suggest that solitary osteochondromas represent real benign tumors $(1,12)$.

Secondary peripheral chondrosarcomas develop from the malignant transformation of osteochondromas which usually occurs within the cartilaginous cap. Genetic mutations are responsible for the development of osteochondromas. Homozygous deletion of EXT1 is present in $80 \%$ of sporadic osteochondromas, whereas germline mutations characterized HME in EXT1 and EXT2 in combination with loss of heterozygosity $(45,46)$. On the contrary, unknown mutations different from EXT mutations give rise to secondary peripheral osteochondromas. After studying 17 patients with secondary peripheral chondrosarcoma, de Andrea et al. found that the most frequent event was the hemizygous loss of EXT1 (70\%) followed by homozygous loss of EXT1 (12\%), no alterations in EXT1 (12\%) and gain of the EXT1 region (6\%). They also demonstrated that cells with functional EXT1 were present in the superficial layer of secondary peripheral chondrosarcoma. In contrast, cells with dysfunctional EXT1 were mostly populating the superficial layer of sporadic osteochondromas and HME. Moreover, the number of cells with functional EXT1 increased with increasing tumor grade. The authors concluded that osteochondroma cells with a homozygous deletion of EXT1 created a niche in the cartilaginous cap or in the perichondrium, in which cells with functional EXT1 acquired unknown mutations giving rise to secondary peripheral chondrosarcoma (47).

\section{Clinical Presentation}

Osteochondroma remains mainly asymptomatic and is usually diagnosed incidentally on radiographs which were obtained for other reasons $(2,4)$. The second most frequent appearance is a painless palpable lump on the involved bone (7). These bumps can produce cosmetic issues, especially at the proximal tibia and the ribs where they are readily evident and palpable (48).

Symptomatic presentation is brought about by mechanical compression of adjacent structures, fracture, bursitis, or malignant transformation (49). Sometimes an osteochondroma might put pressure on a nerve leading to numbness and tingling in the limb $(50,51)$. It may also compress a blood vessel resulting in periodic changes in blood flow, loss of pulse and changes in color of the associated limb. Other vascular complications encompass arterial thrombosis, venous thrombosis, and aneurysm or pseudoaneurysm formation (5256). The popliteal artery, common peroneal nerve, and posterior tibial nerve are the most frequently affected (55-58).

In a few cases, osteochondromas can be located under tendons, creating pain during relevant movements because the tendon might move and break over the bony tumor (4). Occasionally, the compression of the overlying soft tissue may provoke bursal formation and bursitis (7). Spinal osteochondroma may cause kyphosis or spondylolisthesis if they are close to the intervertebral space (59). Spinal cord compression is a rare phenomenon (32) because most of them develop out of the spinal cord $(60,61)$. Finally, the stalk of a pedunculated osteochondroma can snap due to an injury causing pain and swelling (4).

HME is normally diagnosed as a genetic disorder before the age of 12 (4). The median age of diagnosis is 3 years (22). Newborns are asymptomatic, while $50 \%$ of the patients have a visible tumor and get diagnosed by the age of 5 , and $80 \%$ by the age of $10(21)$. There is a variety in size and number of exostoses with a mean number of 6 lesions per patient (23). Diverse valgus deformities can be observed like coxa valga, genu valgum, and ankle valgus $(62,63)$. Other manifestations are inequality in limb length, anomalies of the radio and ulnar deviation, metacarpal, metatarsal, or phalangeal shortening, acetabular dysplasia, femoroacetabular impingement, and juvenile arthritis $(4,6,64)$. Dislocation or subluxation of the hip, patellar, or talus are common 
symptoms (4, 62, 63). Myelopathy due to spinal cord compression occurs more frequently in HME than solitary tumors $(14,65)$. Facial asymmetry and masseters' dysfunction are probably correlated with exostoses of the head and neck $(66,67)$. Complications of costal lesions such as pneumothorax and hemothorax due to injury of an intercostal artery, or diaphragmatic laceration are rare (68-70). Rarely, a growing lesion might cause viscera dysphagia, intestinal obstruction, or urinary tract obstruction $(4,71)$.

\section{Malignant Transformation}

The most dangerous complication of osteochondroma is cancerous transformation which usually happens within the cartilage cap and leads to the development of secondary chondrosarcoma (30). It is estimated that malignant transformation occurs in approximately $1 \%$ of solitary osteochondromas and $10 \%$ of HME cases $(2,6,14,71)$. Rarely, other malignant tumors like osteosarcoma can complicate an osteochondroma (72). Common sites of secondary chondrosarcoma are the proximal femur, proximal humerus, scapula, and pelvis (69). Most of these tumors are low to intermediate grade $(2,73)$.

As a rule, every patient with a new onset of pain near a preexisting osteochondroma should undergo imaging, preferentially MRI, to exclude secondary chondrosarcoma (73). Worrisome imaging features encompass tumor growth after skeletal maturity, irregular or lobulated margins, irregular or scattered calcifications, internal lytic areas, and erosion or destruction of adjacent bones $(5,7,74,75)$. However, the most reliable imaging finding is the thickness of the cartilage cap, which can be evaluated by cross-sectional imaging such as MDCT and MRI $(7,76)$. A cartilage cap thickness greater than $3 \mathrm{~cm}$ in children or $2 \mathrm{~cm}$ in adults is a sign of malignant transformation (7, 77-79). After examining 67 benign osteochondromas and 34 secondary chondrosarcomas, Bernard et al. concluded that if a cartilage cap thickness of $2 \mathrm{~cm}$ is used, the sensitivity and specificity of MRI and MDCT in the differentiation of these tumors are $100 \%$ and $98 \%$ vs $100 \%$ and 95\%, respectively (16). Moreover, chondrosarcoma displays septal enhancement on contrast-enhanced MRI, whereas osteochondroma exhibits only peripheral enhancement $(1,80-82)$.

\section{Radiological Features}

Apart from a detailed history and a full clinical examination, imaging modalities are required for the diagnosis of osteochondroma (4). The key radiological features of osteochondroma are cortical and marrow continuity between the lesion and the parent bone, and a cartilage cap (8). Osteochondroma is usually diagnosed only by radiographs, particularly if it is located at the metaphysis of long bones (1).
However, complex lesions or lesions situated at complex anatomical regions like the shoulder girdle, pelvis, or spine can better be appraised by MDCT or MRI (76).

Analysis by $X$-ray. Plain radiography should be the first imaging modality to assess an osseous lesion. Typically, osteochondroma presents as a well-defined protuberance on the external surface of a bone (Figures 1 and 2). The lesion varies from 1 to $10 \mathrm{~cm}$ and consists of a cortex and a medulla, which are in continuity with the underlying bone $(1,3)$. It can be either sessile or pedunculated. If the tumor sticks out from the bone through a stalk, it is called pedunculated. Pedunculated osteochondromas typically point away from the joint. Otherwise, the tumor lacks a stalk and is attached to the bone with a broad base. In this case, the structure is called sessile $(4,30)$. Another finding is the presence of calcified flakes or linear interruptions inside the cartilaginous component (4).

HME can appear as bilateral tumors that make a metaphysis wider. In the case of tarsal and carpal involvement, a mass emerging from their epiphysis is seen (4). Moreover, several complications are easily recognized in plain radiography like pneumothorax, hemothorax, fracture, joint dislocation, and growth anomalies $(4,83)$.

The problem is whether a lesion should be characterized as benign or malignant. Suspicion for malignant transformation should be raised in the presence of growth of an osteochondroma after the closure of growth plates, irregular or lobulated margin, irregular or scattered calcifications, internal lytic areas, and erosion or destruction of adjacent bones $(5,7,74,75)$.

Analysis by computed tomography $(C T)$. CT is valuable in identifying tumors in areas that are difficult to image on plain radiography such as shoulder, scapula, spine, and pelvis. Besides, CT can assess the size and the extent of spinal lesions in patients presenting with compressive myelopathy (4). CT illustrates bone tumors, the cartilage cap, and calcifications within the cartilage cap or the surrounding soft tissue in detail $(3,4,16)$. Measuring cartilage cap thickness is of utmost importance as a thicker cartilage cap is an indication of malignant degeneration $(72,84)$. One major drawback of CT scanning is the fact that in some cases the thickness of the cartilage cap is overestimated due to the fact that overlying bursa and the cartilage cap may not be well distinguished as both have similar Hounsfield units (16). Another limitation is the lack of estimation of the metabolic activity, a serious indication of malignancy (4).

Analysis by magnetic resonance imaging (MRI). MRI is the best method for imaging the exact morphology of a tumor and all the previously reported complications $(4,77,85)$. The continuity of the parent bone with the cortical and 


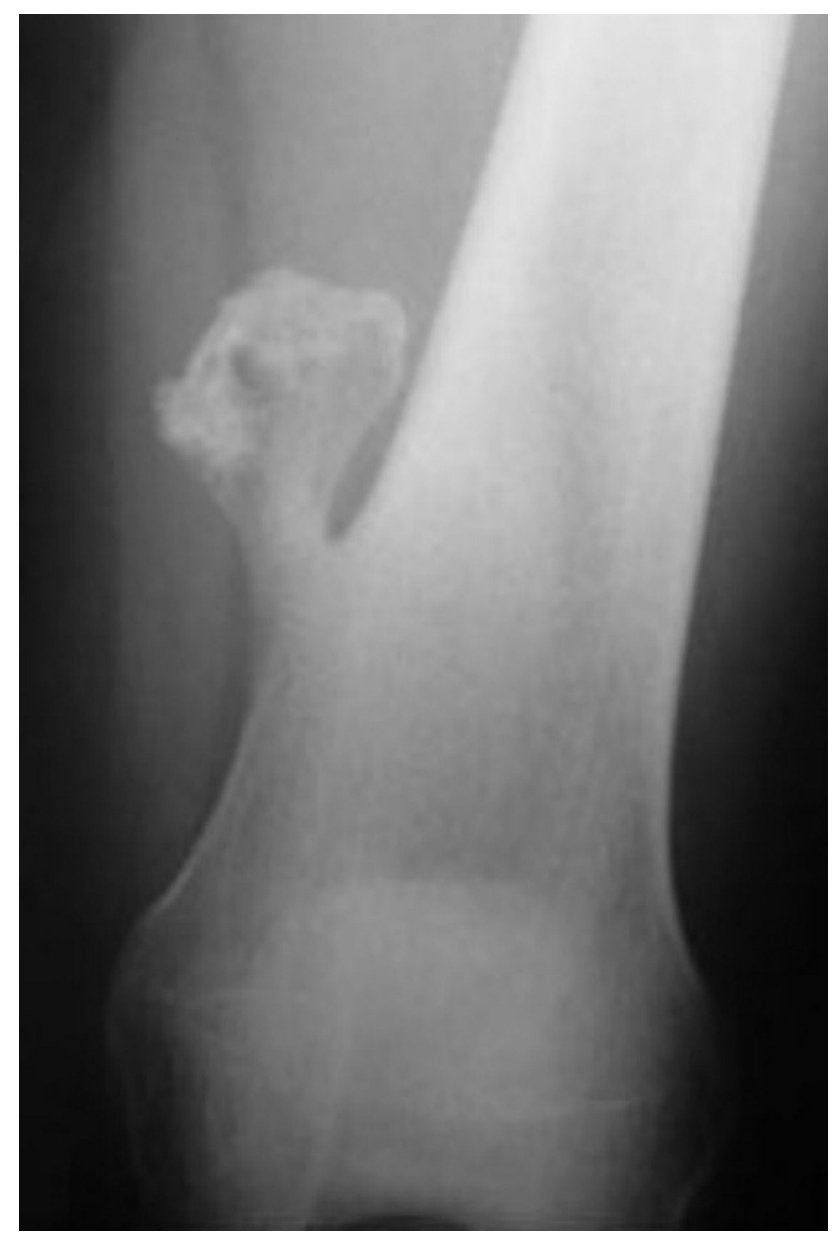

Figure 1. A typical femoral osteochondroma X-ray. Note the protuberance on the external surface of the right femoral bone. Linear calcifications inside the tumor are also apparent. Reprinted with permission from (4).

medullary bone in an osteochondroma plays an essential role in differentiating osteochondromas from other surface bone tumors (15). The cartilage cap has a low intermediate signal on T1-weighted images and high signal on T2-weighted images due to its high-water content (30). Other imaging features include an overlying thin rim of a low signal which represents the perichondrium, areas of a red marrow-like signal within the body stalk, internal septa, and peripheral enhancement after the administration of gadolinium $(1,8,30)$.

MRI gives information about bursitis, muscle impingement, vascular complications, and compression of the spinal cord and nerves $(31,57,77)$. Bursa formation present as an illdefined lesion, filled with fluid, which shows rim enhancement after the administration of gadolinium (85). Muscular impingement shows a high signal within the muscle on T2-weighted images and should be kept in mind in cases

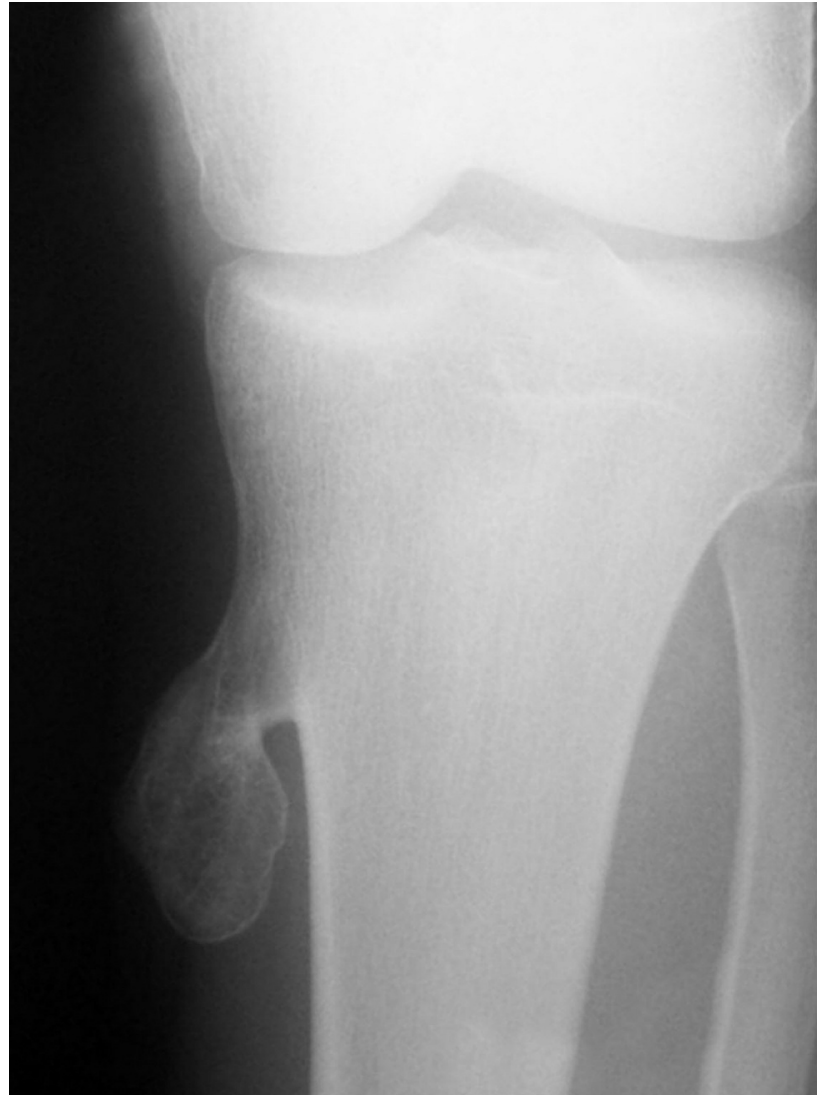

Figure 2. A typical tibial osteochondroma X-ray. Note the protuberance on the external surface of the tibial bone. Reprinted with permission from (4).

of pain and swelling in the region of an exostosis (86). Pseudoaneurysm appears as a heterogenous irregular lesion and a thrombosis as an onion-like formation inside the lumen of the vessel (4).

Finally, MRI ameliorates accuracy in the diagnosis of secondary chondrosarcoma $(87,88)$. A cartilage cap thickness greater than $3 \mathrm{~cm}$ in children or $2 \mathrm{~cm}$ in adults indicates the development of secondary chondrosarcoma (7, 77-79). Moreover, septal enhancement after gadolinium administration suggests malignant degeneration $(1,80-82)$.

Analysis by ultrasound. Ultrasound is another useful tool to evaluate the cartilage cap thickness (89). Cartilage cap appears as a hypoechoic region situated above a hyperechoic bone. Malghem et al. examined 22 resected exostoses and two exostotic chondrosarcomas and demonstrated that ultrasound measurement is very accurate, particularly higher than MDCT and comparable to MRI (90). Ultrasound is also beneficial for the detection of vascular complications such as arterial thrombosis, venous thrombosis, aneurysm or pseudoaneurysm formation as well as the diagnosis of bursitis (18). The main 
limitation of ultrasound is the fact that it remains operator dependent. A further drawback is its inability to portray the cartilage cap when it is inwardly orientated or deeply located in soft tissues, which are both, however, relatively uncommon situations (90).

Analysis by nuclear imaging. Scintigraphy examines the metabolic activity of a tumor and detects new bone lesions through whole-body images in a single examination $(4,91)$. Thalium 201 scintigraphy is useful in distinguishing benign osteochondroma from malignant degeneration in HME (92). Normal isotopic bone scintigraphy rules out the possibility of malignant transformation of an osteochondroma, whereas a positive one is incapable of differentiating endochondral ossification occurring in a benign osteochondroma from the hyperemia and osteoblastic reaction occurring in chondrosarcoma (93).

Analysis by fluorodeoxyglucose positron emission tomography (FDG-PET). FDG-PET may have a role in the differential diagnosis and grading of chondrosarcomas. However, during childhood and adolescence, an abnormal uptake of fluorodeoxyglucose could be found due to the growth of exostoses. Shortcomings of FDG-PET are limited experience, limited availability, and high cost (94).

\section{Treatment}

Currently, there is no medical therapy available for osteochondromas, although biological therapies may be available in the future (10). Retinoid acid receptor gamma $(\operatorname{RAR} \gamma)$ agonists are emerging as a potential treatment for HME. RAR $\gamma$ is a nuclear receptor which also acts as a transcription factor. It plays an essential role in cartilage development and growth. Preclinical studies have shown that the administration of RAR $\gamma$ agonists inhibits heterotopic ossification in mice and rats $(95,96)$. Several preclinical studies have tested the efficacy of RAR $\gamma$ agonists against osteochondromas $(97,98)$. Garcia et al. demonstrated that Palovarotene, a RAR $\gamma$ agonist, stimulated cartilage matrix catabolic genes (ADAMTS5, HES1, AND MMP13) and death genes (CASP4), while it inhibited cartilage matrix anabolic genes (COL2A1, ACAN, and SOX9). These findings suggested that Palovarotene suppressed osteochondromas by inhibiting matrix synthesis, stimulating cartilage cap degradation, and inducing cell death (99). Similarly, Inubushi et al. illustrated that Palovarotene reduced the number of osteochondromas that developed in mice (100). Even though these results are promising, the number of samples is limited, and little is known about the potential side effects of RAR $\gamma$ agonists on growing skeletal tissues. Further studies are needed to establish RAR $\gamma$ agonists as pharmacological therapy for osteochondromas.
Nowadays, the mainstay of conservative treatment is observation initially with plain radiographs and subsequently by clinical examination (6). Further investigation, preferably with MRI, is required if pain develops or the tumor enlarges after the closure of growth plates (80). Even though no study demonstrated the efficacy of screening, one should consider screening patients regularly every year or every other year (6).

Indications for surgical therapy include pain, complications, cosmetic reasons, increased risk of malignant transformation, and uncertain diagnosis $(4,6,10,14,101)$. Myelopathy, radiculopathy, and vascular compression justify surgical excision in the case of spinal osteochondromas $(102,103)$. It is worth noting that patients with HME undergo surgical excision more frequently than patients with solitary osteochondromas due to the increased risk of malignant transformation and severe osseous deformation $(6,16)$, although spontaneous regression of the exostoses has been reported in $30 \%$ of patients with HME (10).

If the tumor is asymptomatic, surgery should not be carried out as the risk of surgery-related complications is higher than tumor-related ones (4). Wirganowicz et al. described the surgical risk for the elective excision of 285 osteochondroma; they found that the complication rate was $12.5 \%$, with neurapraxia being the most common one, followed by arterial laceration, compartment syndrome, and fibula fracture (104). Bottner et al. evaluated the surgical treatment of symptomatic osteochondromas in 86 patients and reported a recurrence rate of $11.6 \%$. Major and minor complications occurred in $4.7 \%$ and $7 \%$ of patients, respectively (105).

Complete resection by removing exostoses at the normal bone base, with consequential removal of the cartilage cap and perichondrium is the recommended intervention. If the resection bed is clear, and there are no remnants of the cartilage cap and perichondrium, the risk of relapse is extremely low $(14,102,106-108)$. Apart from that, there is a likelihood of cancerous degeneration in $1 \%$ of solitary osteochondromas and $10 \%$ of HME; therefore, complete resection is obligatory $(2,6,14,71)$. Donati et al. studied 61 patients suffering from grade I and II secondary peripheral chondrosarcomas of the pelvis; the recurrence rate was $3 \%$ after complete excision compared to $23 \%$ after incomplete resection (109).

In the case of malignancy, en-block resection of the lesion with tumor-free margin should be carried out. Ideally, the procedure should take place in a bone tumor referral centre (6). Metastases are found in approximately 3-7\% of patients and are usually located in the lungs (4). Chemotherapy and radiotherapy are not frequently used in differentiated chondrosarcoma, while in dedifferentiated lesions they are recommended as the prognosis is worse, even though radiotherapy and chemotherapy have a low impact on these tumors $(4,10)$. 
In children, resection might preferably be held up until skeletal maturity is reached because the relapse rate is probably higher in the immature patient $(110,111)$. Great care must be exercised with tumors close to the physeal plate to avoid damage to the growth plate. Ohnishi et al. described the surgical outcomes of 16 patients with digital osteochondromas; the average age of the patients was 3.6 years. The authors concluded that resection is highly recommended for tumors located at the nonepiphyseal metaphysis of the bone to improve motion and prevent further finger deformity. If the tumors are oriented laterally and less than $30 \%$ of the joint surface is involved, resection including part of the articular surface is possible (112).

Reconstructive techniques like bone grafting and internal fixations might be necessary if complete resection is performed in certain regions such as the pelvis (10). Low condylectomy with recontouring of the condylar neck to function as a condyle and repositioning of the articular discs with orthognathic surgery if needed is an option for the treatment of mandibular condylar osteochondroma with jaw deformity $(101,113)$.

Three-dimensional printing is a novel and promising technology for tailoring anatomic models and allowing surgeons to examine anatomy more concretely (114). The printer produces an anatomic model which exhibits lesions challenging to visualize or with complex geometry, tumor features, and the anatomy of adjacent critical structures. Consequently, the surgeons' understanding of anatomic and surgical complexity is improved. However, further research is mandatory to assess the face validity and the efficacy of printouts in surgical planning $(115,116)$.

\section{Prognosis}

Osteochondromas are benign lesions, and thus the prognosis is excellent. The reported local recurrence is less than $2 \%(102$, $110,111,117,118)$. The estimated risk for cancerous degeneration is $1 \%$ and $10 \%$ for solitary osteochondromas and HME, respectively $(2,6,14,71)$. Florez et al. studied 113 solitary osteochondromas treated between 1970 and 2002. The tumors recurred in 6 patients, while in 2 patients they transformed to secondary chondrosarcomas. The authors noted that the recurrence of exostoses is a rare happening in about $2 \%$ of the resections (117). Complications after surgical removal of osteochondromas vary between $11.6 \%$ and $12.5 \%(104,105)$. If secondary peripheral chondrosarcoma develops, the prognosis depends on the histological grade. Ten-year survival for grade I chondrosarcoma is $83 \%$ vs $29 \%$ for grade III (119).

\section{Conclusion}

Osteochondroma is a benign cartilage tumor projecting from the external surface of the bone. It is the most common benign bone tumor and usually occurs in the metaphyseal region of the long bones. In the vast majority of cases, it appears as a solitary lesion, while in $15 \%$ of cases it presents as multiple lesions due to HME, caused by heterozygous loss-of-function mutations in EXT-1 and EXT-2 genes. Although most lesions are asymptomatic, symptoms may result from nerve or vein compression, fractures, bursa formation, osseous deformities, or even malignant transformation. It is estimated that the latter occurs in approximately $1 \%$ of solitary osteochondromas and $10 \%$ of HME. New onset of pain, growth of tumor after skeletal maturity, irregular margins, irregular or scattered calcifications, internal lytic areas, erosion of adjacent bones, cartilage cap thickness $>2 \mathrm{~cm}$ in adults or $>3 \mathrm{~cm}$ in children are signs of cancerous degeneration. Even though plain radiography is usually sufficient for the diagnosis of osteochondromas, crosssectional imaging modalities are useful in the assessment of lesions situated at complex areas, complications, and cartilage cap thickness. Asymptomatic lesions require no treatment, whereas surgical indications encompass symptoms, complications, cosmetic reasons, malignant transformation, or uncertain diagnosis. If complete resection is achieved, the recurrence rate is less than $2 \%$.

\section{Conflicts of Interest}

The Authors report no conflicts of interest.

\section{Authors' Contributions}

Tepelenis K: Analysis and interpretation of data. Troupis T: Study conception and design, drafting of manuscript. Kitsouli A: Literature search and acquisition of data.

Barbouti A: Literature search and acquisition of data. Papathanakos G: Critical revision. Vlachos K: Analysis and interpretation of data. Kanavaros P: Study conception and design, drafting of manuscript. Kitsoulis P: Final approval of the version to be submitted.

\section{References}

1 Murphey MD, Choi JJ, Kransdorf MJ, Flemming DJ and Gannon FH: Imaging of osteochondroma: variants and complications with radiologic-pathologic correlation. Radiographics 20(5): 14071434, 2000. PMID: 10992031. DOI: 10.1148/radiographics. 20.5.g00se 171407

2 Garcia RA, Inwards CY and Unni KK: Benign bone tumors recent developments. Semin Diagn Pathol 28(1): 73-85, 2011. PMID: 21675379. DOI: 10.1053/j.semdp.2011.02.013

3 Brien EW, Mirra JM and Luck JV Jr: Benign and malignant cartilage tumors of bone and joint: their anatomic and theoretical basis with an emphasis on radiology, pathology and clinical biology. II. Juxtacortical cartilage tumors. Skeletal Radiol 28(1): 1-20, 1999. PMID: 10068070. DOI: 10.1007/s002560050466

4 Kitsoulis P, Galani V, Stefanaki K, Paraskevas G, Karatzias G, Agnantis NJ and Bai M: Osteochondromas: review of the clinical, radiological and pathological features. In Vivo 22(5): 633-646, 2008. PMID: 18853760.

5 Wootton-Gorges SL: MR imaging of primary bone tumors and tumor-like conditions in children. MagnReson Imaging Clin N 
Am 17(3): 469-487, 2009. PMID: 19524197. DOI: 10.1016/ j.mric.2009.03.010

6 Bovée JV: Multiple osteochondromas. Orphanet J Rare Dis 3: 3, 2008. PMID: 18271966. DOI: 10.1186/1750-1172-3-3

7 Motamedi K and Seeger LL: Benign bone tumors. Radiol Clin North Am 49(6): 1115-1134, 2011. PMID: 22024291. DOI: 10.1016/j.rcl.2011.07.002

8 Alyas F, James SL, Davies AM and Saifuddin A: The role of MR imaging in the diagnostic characterisation of appendicular bone tumours and tumour-like conditions. Eur Radiol 17(10): 26752686, 2007. PMID: 17342487. DOI: 10.1007/s00330-007-0597-y

9 Saglik Y, Altay M, Unal VS, Basarir K and Yildiz Y: Manifestations and management of osteochondromas: a retrospective analysis of 382 patients. Acta Orthop Belg 72(6): 748-755, 2006. PMID: 17260614.

10 D'Arienzo A, Andreani L, Sacchetti F, Colangeli S and Capanna R: Hereditary Multiple Exostoses: Current Insights. Orthop Res Rev 11: 199-211, 2019. PMID: 31853203. DOI: 10.2147/ ORR.S183979

11 Yang $\mathrm{C}$, Zhang $\mathrm{R}$, Lin $\mathrm{H}$ and Wang $\mathrm{H}$ : Insights into the molecular regulatory network of pathomechanisms in osteochondroma. J Cell Biochem 120(10): 16362-16369, 2019. PMID: 31211456. DOI: $10.1002 /$ jcb.29155

12 Pacifici M: Hereditary multiple exostoses: New insights into pathogenesis, clinical complications, and potential treatments. Curr Osteoporos Rep 15(3): 142-152, 2017. PMID: 28466453. DOI: $10.1007 / \mathrm{s} 11914-017-0355-2$

13 Khare GN: An analysis of indications for surgical excision and complications in 116 consecutive cases of osteochondroma. Musculoskelet Surg 95(2): 121-125, 2011. PMID: 21667172. DOI: $10.1007 / \mathrm{s} 12306-011-0143-6$

14 Lotfinia I, Vahedi P, Tubbs RS, Ghavame M and Meshkini A: Neurological manifestations, imaging characteristics, and surgical outcome of intraspinal osteochondroma. J Neurosurg Spine 12(5): 474-489, 2010. PMID: 20433295. DOI: 10.3171/ 2009.11.SPINE0980

15 Mehta M, White LM, Knapp T, Kandel RA, Wunder JS and Bell RS: MR imaging of symptomatic osteochondromas with pathological correlation. Skeletal Radiol 27(8): 427-433, 1998. PMID: 9765135. DOI: 10.1007/s002560050412

16 Bernard SA, Murphey MD, Flemming DJ and Kransdorf MJ: Improved differentiation of benign osteochondromas from secondary chondrosarcomas with standardized measurement of cartilage cap at CT and MR imaging. Radiology 255(3): 857-865, 2010. PMID: 20392983. DOI: 10.1148/radiol.10082120

17 Subbarao K: Benign tumors of bone. Nepal J Radiol 2(1): 1-12, 2012.

18 Hakim DN, Pelly T, Kulendran M and Caris JA : Benign tumours of the bone: A review. J Bone Oncol 4(2): 37-41, 2015. PMID: 26579486. DOI: 10.1016/j.jbo.2015.02.001

19 Chatzidakis E, Lypiridis S, Kazdaglis G, Chatzikonstadinou K and Papatheodorou G: A rare case of solitary osteochondroma of the dens of the C2 vertebra. Acta Neurochir (Wien) 149(6): 637638, 2007. PMID: 17450439. DOI: 10.1007/s00701-007-1151-z

20 Govender $\mathrm{S}$ and Parbhoo AH: Osteochondroma with compression of the spinal cord. A report of two cases. J Bone Joint Surg Br 81(4): 667-669, 1999. PMID: 10463742. DOI: 10.1302/0301-620x.81b4.9248

21 Ryckx A, Somers JF and Allaert L: Hereditary multiple exostosis. Acta Orthop Belg 79(6): 597-607, 2013. PMID: 24563962.
22 Schmale GA, Conrad EU 3rd and Raskind WH: The natural history of hereditary multiple exostoses. J Bone Joint Surg Am 76(7): 986-992, 1994. PMID: 8027127. DOI: 10.2106/00004623199407000-00005

23 Hennekam RC: Hereditary multiple exostoses. J MedGenet 28(4): 262-266, 1991. PMID: 1856833. DOI: 10.1136/ jmg.28.4.262

24 Nawata K, Teshima R, Minamizaki T and Yamamoto K: Knee deformities in multiple hereditary exostoses. A longitudinal radiographic study. Clin Orthop Relat Res 313: 194-199, 1995. PMID: 7641480.

25 Legeai-Mallet L, Munnich A, Maroteaux P and Le Merrer M: Incomplete penetrance and expressivity skewing in hereditary multiple exostoses. Clin Genet 52(1): 12-16, 1997. PMID: 9272707. DOI: 10.1111/j.1399-0004.1997.tb02508.x

26 Volpi N, Dotti MT, Giannini F, Cappelli B, Terrosi Vagnoli P and Federico A: Familial multiple exostoses syndrome: a phacomatosis of bone tissue. Acta Neurol (Napoli) 8(5): 516-527, 1986. PMID: 3492091.

27 Wood VE, Sauser D and Mudge D: The treatment of hereditary multiple exostosis of the upper extremity. J Hand Surg Am 10(4): 505-513,1985. PMID: 3874896. DOI: 10.1016/s0363-5023(85) $80074-5$

28 Tong K, Liu H, Wang X, Zhong Z, Cao S, Zhong C, Yang Y and Wang G: Osteochondroma: Review of 431 patients from one medical institution in South China. J Bone Oncol 30: 23-29, 2017. PMID: 28932679. DOI: 10.1016/j.jbo.2017.08.002

29 Galasso O, Mariconda M and Milano C: An enlarging distal tibia osteochondroma in the adult patient. J Am Podiatr Med Assoc 99(2): 157-161, 2009. PMID: 19299355. DOI: 10.7547/ 0980157

30 Douis $\mathrm{H}$ and Saifuddin A: The imaging of cartilaginous bone tumours. I. Benign lesions. Skeletal Radiol 41(10): 1195-1212, 2012. PMID: 22707094. DOI: 10.1007/s00256-012-1427-0

31 Roach JW, Klatt JW and Faulkner ND: Involvement of the spine in patients with multiple hereditary exostoses. J Bone Joint Surg Am 91(8): 1942-1948, 2009. PMID: 19651953. DOI: 10.2106/JBJS.H.00762

32 Maheshwari AV, Jain AK and Dhammi IK: Osteochondroma of C7 vertebra presenting as compressive myelopathy in a patient with nonhereditary (nonfamilial/sporadic) multiple exostoses. Arch Orthop Trauma Surg 126(10): 654-659, 2006. PMID: 16906423. DOI: 10.1007/s00402-006-0211-9

33 Sakai D, Mochida J, Toh E and Nomura T: Spinal osteochondromas in middle-aged to elderly patients. Spine (Phila Pa 1976) 27(23): E503-E506, 2002. PMID: 12461407. DOI: 10.1097/00007632-200212010-00017

34 Bess RS, Robbin MR, Bohlman HH and Thompson GH: Spinal exostoses: analysis of twelve cases and review of the literature. Spine (Phila Pa 1976) 30(7): 774-780, 2005. PMID: 15803080. DOI: 10.1097/01.brs.0000157476.16579.a2

35 Mordenti M, Shih F, Boarini M, Pedrini E, Gnoli M, Antonioli D, Tremosini M and Sangiorgi L: The natural history of multiple osteochondromas in a large Italian cohort of pediatric patients. Bone 139: 115499, 2020. PMID: 32592948. DOI: 10.1016/ j.bone.2020.115499

36 Hall CR, Cole WG, Haynes R and Hecht JT: Reevaluation of a genetic model for the development of exostosis in hereditary multiple exostosis. Am J Med Genet 112(1): 1-5, 2002. PMID: 12239711. DOI: 10.1002/ajmg.10635 
37 Francannet C, Cohen-Tanugi A, Le Merrer M, Munnich A, Bonaventure $\mathrm{J}$ and Legeai-Mallet L: Genotype-phenotype correlation in hereditary multiple exostoses. J Med Genet 38(7): 430-434, 2001. PMID: 11432960. DOI: 10.1136/jmg.38.7.430

38 Pei Y, Wang Y, Huang W, Hu B, Huang D, Zhou Y and Su P: Novel mutations of EXT1 and EXT2 genes among families and sporadic cases with multiple exostoses. Genet Test Mol Biomarkers 14(6): 865-872, 2010. PMID: 21039224. DOI: $10.1089 / \mathrm{gtmb} .2010 .0040$

39 Bishop JR, Schuksz M and Esko JD: Heparan sulphate proteoglycans fine-tune mammalian physiology. Nature 446(7139): 1030-1037, 2007. PMID: 17460664. DOI: 10.1038/ nature 05817

40 Esko JD and Selleck SB: Order out of chaos: assembly of ligand binding sites in heparan sulfate. Annu Rev Biochem 71: 435-471, 2002. PMID: 12045103. DOI: 10.1146/annurev.biochem. 71.110601 .135458

41 Porter DE, Lonie L, Fraser M, Dobson-Stone C, Porter JR, Monaco AP and Simpson AH: Severity of disease and risk of malignant change in hereditary multiple exostoses. A genotypephenotype study. J Bone Joint Surg Br 86(7): 1041-1046, 2004. PMID: 15446535. DOI: 10.1302/0301-620x.86b7.14815

42 Huegel J, Sgariglia F, Enomoto-Iwamoto M, Koyama E, Dormans JP and Pacifici M: Heparan sulfate in skeletal development, growth, and pathology: the case of hereditary multiple exostoses. Dev Dyn 242(9): 1021-1032, 2013. PMID: 23821404. DOI: $10.1002 /$ dvdy. 24010

43 Chen Z, Ruan W, Li M, Cao L, Lu J, Zhong F and Bi Q: A novel nonsense mutation in the EXT2 gene identified in a family with hereditary multiple osteochondromas. Genet Test Mol Biomarkers 24(8): 478-483, 2020. PMID: 32678989. DOI: 10.1089/gtmb.2020.0017

44 Oliver GR, Blackburn PR, Ellingson MS, Conboy E, Pinto E Vairo F, Webley M, Thorland E, Ferber M, Van Hul E, van der Werf IM, Wuyts W, Babovic-Vuksanovic D and Klee EW: RNASeq detects a SAMD12-EXT1 fusion transcript and leads to the discovery of an EXT1 deletion in a child with multiple osteochondromas. Mol Genet Genomic Med 7(3): e00560, 2019. PMID: 30632316. DOI: $10.1002 / \mathrm{mgg} 3.560$

45 Zuntini M, Pedrini E, Parra A, Sgariglia F, Gentile FV, Pandolfi M, Alberghini M and Sangiorgi L: Genetic models of osteochondroma onset and neoplastic progression: evidence for mechanisms alternative to EXT genes inactivation. Oncogene 29(26): 38273834, 2010. PMID: 20418910. DOI: 10.1038/onc.2010.135

46 Reijnders CM, Waaijer CJ, Hamilton A, Buddingh EP, Dijkstra SP, Ham J, Bakker E, Szuhai K, Karperien M, Hogendoorn PC, Stringer SE and Bovée JV: No haploinsufficiency but loss of heterozygosity for EXT in multiple osteochondromas. Am J Pathol 177(4): 1946-1957, 2010. PMID: 20813973. DOI: 10.2353/ajpath.2010.100296

47 de Andrea CE, Reijnders CM, Kroon HM, de Jong D, Hogendoorn PC, Szuhai K and Bovée JV: Secondary peripheral chondrosarcoma evolving from osteochondroma as a result of outgrowth of cells with functional EXT. Oncogene 31(9): 10951104, 2012. PMID: 21804604. DOI: 10.1038/onc.2011.311

48 Ali S, Kaplan S, Kaufman T, Fenerty S, Kozin S and Zlotolow DA: Madelung deformity and Madelung-type deformities: a review of the clinical and radiological characteristics. Pediatr Radiol 45(12): 1856-1863, 2015. PMID: 26135644. DOI: $10.1007 / \mathrm{s} 00247-015-3390-0$
49 Gavanier M and Blum A: Imaging of benign complications of exostoses of the shoulder, pelvic girdles and appendicular skeleton. Diagn Interv Imaging 98(1): 21-28, 2017. PMID: 27316575. DOI: 10.1016/j.diii.2015.11.021

50 Mnif H, Koubaa M, Zrig M, Zammel N and Abid A: Peroneal nerve palsy resulting from fibular head osteochondroma. Orthopedics 32(7): 528, 2009. PMID: 19634838. DOI: 10.3928/ 01477447-20090527-24

51 Van Oost J, Feyen J and Opheide J: Compartment syndrome associated with an osteocartilaginous exostosis. Acta Orthop Belg 62(4): 233-235, 1996. PMID: 9008968

52 Vallance R, Hamblen DL and Kelly IG: Vascular complications of osteochondroma. Clin Radiol 36(6): 639-642, 1985. PMID: 4064551. DOI: $10.1016 / \mathrm{s} 0009-9260(85) 80257-9$

53 Sakata T, Mogi K, Sakurai M, Nomura A, Fujii M and Takahara Y: Popliteal Artery Pseudoaneurysm Caused by Osteochondroma. Ann Vasc Surg 43: 313.e5-313.e7, 2017. PMID: 28478169. DOI: 10.1016/j.avsg.2017.04.003

54 Raherinantenaina F, Rakoto-Ratsimba HN and Rajaonanahary TM: Management of extremity arterial pseudoaneurysms associated with osteochondromas. Vascular 24(6): 628-637, 2016. PMID: 26944530. DOI: 10.1177/1708538116634532

55 Vasseur MA and Fabre O: Vascular complications of osteochondromas. J Vasc Surg 31(3): 532-538, 2000. PMID: 10709067.

56 Perez-Burkhardt JL and Gómez Castilla JC: Postraumatic popliteal pseudoaneurysm from femoral osteochondroma: case report and review of the literature. J Vasc Surg 37(3): 669-671, 2003. PMID: 12618708 . DOI: $0.1067 / \mathrm{mva} .2003 .48$

57 Göçmen S, Topuz AK, Atabey C, Şimşek H, Keklikçi K and Rodop O: Peripheral nerve injuries due to osteochondromas: analysis of 20 cases and review of the literature. J Neurosurg 120(5): 1105-1112, 2014. PMID: 24405073. DOI: 10.3171/ 2013.11.JNS13310

58 Cardelia JM, Dormans JP, Drummond DS, Davidson RS, Duhaime $\mathrm{C}$ and Sutton L: Proximal fibular osteochondroma with associated peroneal nerve palsy: a review of six cases. J Pediatr Orthop 15(5): 574-577, 1995. PMID: 7593564. DOI: 10.1097/ 01241398-199509000-00004

59 Quirini GE, Meyer JR, Herman M and Russell EJ: Osteochondroma of the thoracic spine: an unusual cause of spinal cord compression. AJNR Am J Neuroradiol 17(5): 961-964, 1996. PMID: 8733974.

60 Fiumara E, Scarabino T, Guglielmi G, Bisceglia M and D'Angelo V: Osteochondroma of the L-5 vertebra: a rare cause of sciatic pain. Case report. J Neurosurg 91(2 Suppl): 219-222, 1999. PMID: 10505509. DOI: 10.3171/spi.1999.91.2.0219

61 Ohtori S, Yamagata M, Hanaoka E, Suzuki H, Takahashi K, Sameda $\mathrm{H}$ and Moriya H: Osteochondroma in the lumbar spinal canal causing sciatic pain: report of two cases. J Orthop Sci 8(1): 112-115, 2003. PMID: 12560897. DOI: 10.1007/s007760300019

62 Clement ND and Porter DE: Can deformity of the knee and longitudinal growth of the leg be predicted in patients with hereditary multiple exostoses? A cross-sectional study. Knee 21(1): 299-303, 2014. PMID: 23177660. DOI: 10.1016/ j.knee.2012.10.029

63 Noonan KJ, Feinberg JR, Levenda A, Snead J and Wurtz LD: Natural history of multiple hereditary osteochondromatosis of the lower extremity and ankle. J Pediatr Orthop 22(1): 120-124, 2002. PMID: 11744867. 
64 Wang YZ, Park KW, Oh CS, Ahn YS, Kang QL, Jung ST and Song HR: Developmental pattern of the hip in patients with hereditary multiple exostoses. BMC Musculoskelet Disord 16: 54, 2015. PMID: 25888017. DOI: 10.1186/s12891-015-0514-5

65 Pandya NK, Auerbach JD, Baldwin K, Lackman RD and Chin KR: Spinal cord compression in a patient with multiple hereditary exostoses caused by breast adenocarcinoma metastatic to osteochondromas of the spine: case report. Spine (Phila $\mathrm{Pa}$ 1976) 31(24): E920-E924, 2006. PMID: 17108823. DOI: 10.1097/01.brs.0000245926.30594.bf

66 Koga M, Toyofuku S, Nakamura Y, Yoshiura K, Kusukawa J and Nakamura Y: Osteochondroma in the mandibular condyle that caused facial asymmetry: a case report. Cranio 24(1): 67-70, 2006. PMID: 16541848. DOI: 10.1179/crn.2006.011

67 Koehl GL and Tilson HB: Osteochondromas associated with facial asymmetry and masticatory dysfunction: report of two cases. J Oral Surg 35(11): 934-939, 1977. PMID: 269942.

68 Huang HR, Lin TY and Wong KS: Costal exostosis presenting with hemothorax: report of one case. Eur J Pediatr 165(5): 342343, 2006. PMID: 16435130. DOI: 10.1007/s00431-005-0060-5

69 Khosla A and Parry RL: Costal osteochondroma causing pneumothorax in an adolescent: a case report and review of the literature. J Pediatr Surg 45(11): 2250-2253, 2010. PMID: 21034955. DOI: 10.1016/j.jpedsurg.2010.06.045

70 Jin W, Hyun SY, Ryoo E, Lim YS and Kim JK: Costal osteochondroma presenting as haemothorax and diaphragmatic laceration. Pediatr Radiol 35(7): 706-709, 2005. PMID: 15806405. DOI: $10.1007 / \mathrm{s} 00247-005-1407-9$

71 Abdullah F, Kanard R, Femino D, Ford H and Stein J: Osteochondroma causing diaphragmatic rupture and bowel obstruction in a 14-year-old boy. Pediatr Surg Int 22(4): 401-403, 2006. PMID: 16395607. DOI: 10.1007/s00383-005-1622-3

72 Lamovec J, Spiler M and Jevtic V: Osteosarcoma arising in a solitary osteochondroma of the fibula. Arch Pathol Lab Med 123(9): 832-834, 1999. PMID: 10458834. DOI: 10.1043/00039985(1999) $123<0832$ :OAIASO>2.0.CO;2

73 Lin PP, Moussallem CD and Deavers MT: Secondary chondrosarcoma. J Am Acad Orthop Surg 18: 608-615, 2010. PMID: 20889950. DOI: 10.5435/00124635-201010000-00004

74 Ahmed AR, Tan TS, Unni KK, Collins MS, Wenger DE and Sim FH: Secondary chondrosarcoma in osteochondroma: report of 107 patients. Clin Orthop Relat Res 411: 193-206, 2003. PMID: 12782876. DOI: 10.1097/01.blo.0000069888.31220.2b

75 Porter DE, Emerton ME, Villanueva-Lopez F and Simpson AH: Cli12, nical and radiographic analysis of osteochondromas and growth disturbance in hereditary multiple exostoses. J Pediatr Orthop 20(2): 246-250, 2000. PMID: 10739291.

76 Kwee RM, Fayad LM, Fishman EK and Fritz J: Multidetector computed tomography in the evaluation of hereditary multiple exostoses. Eur J Radiol 85(2): 383-391, 2016. PMID: 26781144. DOI: $10.1016 /$ j.ejrad.2015.11.034

77 Woertler K, Lindner N, Gosheger G, Brinkschmidt C and Heindel W: Osteochondroma: MR imaging of tumor-related complications. Eur Radiol 10(5): 832-840, 2000. PMID: 10823643. DOI: $10.1007 / \mathrm{s} 003300051014$

78 Azouz EM: Magnetic resonance imaging of benign bone lesions: cysts and tumors. Top Magn Reson Imaging 13(4): 219-229, 2002. PMID: 12409690. DOI: 10.1097/00002142-200208000-00003

79 Stacy GS, Heck RK, Peabody TD and Dixon LB: Neoplastic and tumorlike lesions detected on MR imaging of the knee in patients with suspected internal derangement: Part I, intraosseous entities. AJR Am J Roentgenol 178(3): 589-594, 2002. PMID: 11856679. DOI: 10.2214/ajr.178.3.1780589

80 Hameetman L, Bovée JV, Taminiau AH, Kroon HM and Hogendoorn PC: Multiple osteochondromas: clinicopathological and genetic spectrum and suggestions for clinical management Hered Cancer Clin Pract 2(4): 161-173, 2004. PMID: 20233460 DOI: $10.1186 / 1897-4287-2-4-161$

81 Khosla A, Martin DS and Awwad EE: The solitary intraspinal vertebral osteochondroma. An unusual cause of compressive myelopathy: features and literature review. Spine (Phila Pa 1976) 24(1): 77-81, 1999. PMID: 9921596. DOI: 10.1097/00007632199901010-00019

82 Sil K, Basu S, Bhattacharya M and Chatterjee S: Pediatric spinal osteochondromas: case report and review of literature. J Pediatr Neurosci 1: 70-71, 2006.

83 Marcove RC and Huvos AG: Cartilaginous tumors of the ribs. Cancer 27(4): 794-801, 1971. PMID: 5574069. DOI: 10.1002/ 1097-0142(197104)27:4<794::aid-cncr2820270406>3.0.co;2-c

84 Robbin MR and Murphey MD: Benign chondroid neoplasms of bone. Semin Musculoskelet Radiol 4(1): 45-58, 2000. PMID: 11061691. Doi: 10.1055/s-2000-6854

85 Lee KC, Davies AM and Cassar-Pullicino VN: Imaging the complications of osteochondromas. Clin Radiol 57(1): 18-28, 2002. PMID: 11798198. DOI: 10.1053/crad.2001.0719

86 Uri DS, Dalinka MK and Kneeland JB: Muscle impingement: MR imaging of a painful complication of osteochondromas Skeletal Radiol 25(7): 689-692, 1996. PMID: 8915059. DOI: $10.1007 / \mathrm{s} 002560050161$

87 De Beuckeleer LH, De Schepper AM and Ramon F: Magnetic resonance imaging of cartilaginous tumors: is it useful or necessary? Skeletal Radiol 25(2): 137-141, 1996. PMID: 8848742. DOI: $10.1007 / \mathrm{s} 002560050050$

88 Geirnaerdt MJ, Hogendoorn PC, Bloem JL, Taminiau AH and van der Woude HJ: Cartilaginous tumors: fast contrast-enhanced MR imaging. Radiology 214(2): 539-546, 2000. PMID: 10671608. DOI: 10.1148/radiology.214.2.r00fe12539

89 Cho KH, Park BH and Yeon KM: Ultrasound of the adult hip. Semin Ultrasound CT MR 21(3): 214-230, 2000. PMID: 10994690. DOI: 10.1016/s0887-2171(00)90044-1

90 Malghem J, Vande Berg B, Noël H and Maldague B: Benign osteochondromas and exostotic chondrosarcomas: evaluation of cartilage cap thickness by ultrasound. Skeletal Radiol 21(1): 3337, 1992. PMID: 1546334. DOI: 10.1007/BF00243091

91 Sánchez-Rodríguez V, Medina-Romero F, Gómez RodríguezBethencourt MÁ, González Díaz MA, González Soto MJ and Alarcó Hernández R: Value of the bone scintigraphy in multiple osteochrondromatosis with sarcomatous degeneration. Rev Esp Med Nucl Imagen Mol 31(5): 270-274, 2012. PMID: 23067530 DOI: $10.1016 /$ j.remn.2011.10.011

92 Tani A, Tsuchimochi S, Nakabeppu Y and Nakajo M: Bone and Tl-201 scintigraphy in a case of hereditary multiple exostoses. Clin Nucl Med 26(12): 1028-1031, 2001. PMID: 11711707. DOI: 10.1097/00003072-200112000-00008

93 Hudson TM, Chew FS and Manaster BJ: Scintigraphy of benign exostoses and exostotic chondrosarcomas. AJR Am J Roentgenol 140(3): 581-586, 1983. PMID: 6600555. DOI: 10.2214/ajr. 140.3.581

94 Aoki J, Watanabe $\mathrm{H}$, Shinozaki T, Tokunaga $\mathrm{M}$, Inoue $\mathrm{T}$ and Endo K: FDG-PET in differential diagnosis and grading of 
chondrosarcomas. J Comput Assist Tomogr 23(4): 603-608, 1999. PMID: 10433294. DOI: 10.1097/00004728-19990700000022

95 Williams JA, Kondo N, Okabe T, Takeshita N, Pilchak DM, Koyama E, Ochiai T, Jensen D, Chu ML, Kane MA, Napoli JL, Enomoto-Iwamoto M, Ghyselinck N, Chambon P, Pacifici M and Iwamoto M: Retinoic acid receptors are required for skeletal growth, matrix homeostasis and growth plate function in postnatal mouse. Dev Biol 328(2): 315-327, 2009. PMID: 19389355. DOI: 10.1016/j.ydbio.2009.01.031

96 Koyama E, Golden EB, Kirsch T, Adams SL, Chandraratna RA, Michaille JJ and Pacifici M: Retinoid signaling is required for chondrocyte maturation and endochondral bone formation during limb skeletogenesis. Dev Biol 208(2): 375-391, 1999. PMID: 10191052. DOI: 10.1006/dbio.1999.9207

97 Shimono K, Tung WE, Macolino C, Chi AH, Didizian JH, Mundy C, Chandraratna RA, Mishina Y, Enomoto-Iwamoto M, Pacifici $\mathrm{M}$ and Iwamoto $\mathrm{M}$ : Potent inhibition of heterotopic ossification by nuclear retinoic acid receptor- $\gamma$ agonists. Nat Med 17(4): 454-460, 2011. PMID: 21460849. DOI: 10.1038/nm.2334

98 Pavey GJ, Qureshi AT, Tomasino AM, Honnold CL, Bishop DK, Agarwal S, Loder S, Levi B, Pacifici M, Iwamoto M, Potter BK, Davis TA and Forsberg JA: Targeted stimulation of retinoic acid receptor- $\gamma$ mitigates the formation of heterotopic ossification in an established blast-related traumatic injury model. Bone 90: 159167, 2016. PMID: 27368930. DOI: 10.1016/j.bone.2016.06.014

99 Garcia SA, Tian H, Imamura-Kawasawa Y, Fisher A, Cellini A, Codd C, Herzenberg JE, Abzug JM, Ng V, Iwamoto M and Enomoto-Iwamoto M: Understanding the action of RAR $\gamma$ agonists on human osteochondroma explants. Int J Mol Sci 21(8): 2686, 2020. PMID: 32294904. DOI: 10.3390/ijms 2108 2686

100 Inubushi T, Lemire I, Irie F and Yamaguchi Y: Palovarotene inhibits osteochondroma formation in a mouse model of multiple hereditary exostoses. J Bone Miner Res 33(4): 658-666, 2018. PMID: 29120519. DOI: 10.1002/jbmr.3341

101 Wolford LM, Movahed R, Dhameja A and Allen WR: Low condylectomy and orthognathic surgery to treat mandibular condylar osteochondroma: a retrospective review of 37 cases. J Oral Maxillofac Surg 72(9): 1704-1728, 2014. PMID: 24997022. DOI: 10.1016/j.joms.2014.03.009

102 Yakkanti R, Onyekwelu I, Carreon LY and Dimar JR 2nd: Solitary osteochondroma of the spine-a case series: Review of solitary osteochondroma with myelopathic symptoms. Global Spine J 8(4): 323-339, 2018. PMID: 29977716. DOI: 10.1177/ 2192568217701096

103 Fukushi R, Emori M, Iesato N, Kano M and Yamashita T: Osteochondroma causing cervical spinal cord compression. Skeletal Radiol 46(8): 1125-1130, 2017. PMID: 28337505. DOI: 10.1007/s00256-017-2633-6

104 Wirganowicz PZ and Watts HG: Surgical risk for elective excision of benign exostoses. J Pediatr Orthop 17(4): 455-459, 1997. PMID: 9364382.

105 Bottner F, Rodl R, Kordish I, Winklemann W, Gosheger G and Lindner N: Surgical treatment of symptomatic osteochondroma. A three- to eight-year follow-up study. J Bone Joint Surg Br 85(8): 1161-1165, 2003. PMID: 14653600. DOI: 10.1302/0301$620 \mathrm{x} .85 \mathrm{~b} 8.14059$

106 Karasick D, Schweitzer ME and Eschelman DJ: Symptomatic osteochondromas: imaging features. AJR Am J Roentgenol
168(6): 1507-1512, 1997. PMID: 9168715. DOI: 10.2214/ ajr.168.6.9168715

107 Arasil E, Erdem A and Yüceer N: Osteochondroma of the upper cervical spine. A case report. Spine (Phila Pa 1976) 21(4): 516518, 1996. PMID: 8658258. DOI: 10.1097/00007632-19960 2150-00021

108 Xing SG and Mao T: Surgical excision of enchondromas and osteochondromas in the hand under local anaesthesia without tourniquet. J Hand Surg Eur Vol 44(7): 745-747, 2019. PMID: 31033376. DOI: $10.1177 / 1753193419845254$

109 Donati D, El Ghoneimy A, Bertoni F, Di Bella C and Mercuri M: Surgical treatment and outcome of conventional pelvic chondrosarcoma. J Bone Joint Surg Br 87(11): 1527-1530, 2005. PMID: 16260673. DOI: 10.1302/0301-620X.87B11.16621

110 Day FN, Ruggieri C and Britton C: Recurrent osteochondroma. J Foot Ankle Surg 37(2): 162-173, 1998. PMID: 9571465. DOI: 10.1016/s1067-2516(98)80097-5

111 Rajappa S, Kumar MM and Shanmugapriya S: Recurrent solitary osteochondroma of the metacarpal: a case report. J Orthop Surg (Hong Kong) 21(1): 129-131, 2013. PMID: 23630007. DOI: $10.1177 / 230949901302100133$

112 Ohnishi T, Horii E, Shukuki K and Hattori T: Surgical treatment for osteochondromas in pediatric digits. J Hand Surg Am 36(3): 432-438, 2011. PMID: 21333463. DOI: doi: 10.1016/j.jhsa. 2010.11.038

113 Friedrich RE, Scheuer HA, Fuhrmann A, Hagel C and Zustin J: Osteochondroma of the mandibular condyle. Report of a case with 5-year follow-up. Anticancer Res 32(10): 4553-4556, 2012. PMID: 23060585.

114 Starosolski ZA, Kan JH, Rosenfeld SD, Krishnamurthy R and Annapragada A: Application of 3-D printing (rapid prototyping) for creating physical models of pediatric orthopedic disorders. Pediatr Radiol 44(2): 216-221, 2014. PMID: 24202430. DOI: 10.1007/s00247-013-2788-9

115 Zhang Y, Wen L, Zhang J, Yan G, Zhou Y and Huang B: Threedimensional printing and computer navigation assisted hemipelvectomy for en bloc resection of osteochondroma: A case report. Medicine (Baltimore) 96(12): e6414, 2017. PMID: 28328842. DOI: 10.1097/MD.0000000000006414

116 Tam MD, Laycock SD, Bell D and Chojnowski A: 3-D printout of a DICOM file to aid surgical planning in a 6 year old patient with a large scapular osteochondroma complicating congenital diaphyseal aclasia. J Radiol Case Rep 6(1): 31-37, 2012. PMID: 22690278. DOI: 10.3941/jrcr.v6i1.889

117 Florez B, Mönckeberg J, Castillo G and Beguiristain J: Solitary osteochondroma long-term follow-up. J Pediatr Orthop B 17(2): 9194, 2008. PMID: 18510166. DOI: 10.1097/bpb.0b013e3282f450c3

118 Bakhshi H, Kushare I, Murphy MO, Gaynor JW and Dormans JP: Chest wall osteochondroma in children: a case series of surgical management. J Pediatr Orthop 34(7): 733-737, 2014. PMID: 25210940. DOI: 10.1097/BPO.0000000000000153

119 Evans HL, Ayala AG and Romsdahl MM: Prognostic factors in chondrosarcoma of bone: a clinicopathologic analysis with emphasis on histologic grading. Cancer 40(2): 818-831, 1977. PMID: 890662. DOI: 10.1002/1097-0142(197708)40:2<818::aidcncr2820400234>3.0.co;2-b

Received December 2, 2020

Revised December 20, 2020

Accepted December 21, 2020 